\title{
O DESENVOLVIMENTO SOCIOECONÔMICO E AS TENSÕES ENTRE OS IDEAIS AMADORES E PROFISSIONAIS NO FUTEBOL BRASILEIRO
}

\section{SOCIOECONOMIC DEVELOPMENT AND TENSIONS BETWEEN AMATEUR AND PROFESSIONAL IDEALS IN BRAZILIAN SOCCER}

\author{
José Geraldo do Carmo Salles* \\ Israel Teoldo da Costa ${ }^{* *}$ \\ Antonio Jorge Gonçalves Soares ${ }^{* * *}$
}

"A avareza, ou o desejo de ganho, é uma paixão universal que age em todos os tempos, em todos os lugares, e sobre todas as pessoas". (David Hume)

\section{RESUMO}

O esporte moderno nasce no seio das escolas públicas inglesas como mais um princípio do processo educativo. Neste contexto educacional o esporte passa a representar uma forma civilizadora de polir os instintos humanos (agressividade, violência, paixão etc), tal como concebe Elias (1992). Todavia, rapidamente tornou-se também um ramo da ordem capitalista, onde a lógica basal é o acúmulo. E o esporte, ao ser governado pelos interesses passou a ser um local de negócios, apostas e divertimentos. O objetivo deste texto é promover a reflexão sobre o processo de desenvolvimento do futebol no Brasil, focado nas tensões entre os ideais amadores e os valores do profissionalismo. O esporte a partir do momento em que assumiu o profissionalismo passou a conviver com sentimentos e significados, à primeira vista, antagônicos e inconciliáveis: interesse financeiro e paixão. Para sustentar as hipóteses apresentamos argumentações da mídia e dos torcedores que reforçam a permanência dos ideais amadores nos pressupostos utilizados acerca das transferências de dois jogadores brasileiros para o futebol europeu. O primeiro, Ronaldo Luís Nazário de Lima (o Fenômeno), que jogou em muitos equipes europeias, o segundo é Neymar da Silva Santos Junior que foi comprado junto ao Santos F. C. pelo F. C. Barcelona em 2013.

Palavras-chave: Futebol, paixão, mídia, esporte e economia.

\begin{abstract}
The modern sport is born within the English public schools as another principle of the educational process. In this educational context the sport come to represent a civilizing way of polishing human instincts (aggression, violence, passion, etc.), as conceived Elias (1992) However, it quickly became also a branch of the capitalist order, where the basal logic is the accumulation. And the sport, to be governed by the interest became a place of business, gaming and entertainment. The aim of this paper is to promote reflection on the process of development of football in Brazil, focused on the tensions between the amateur ideals and values of professionalism. The sport, from the moment in which it assumed the professionalism, went to
\end{abstract}

\footnotetext{
“Doutor em Educação Física pela Universidade Gama Filho - Professor Associado do Departamento de Educação Física - NUPEF - Núcleo de Pesquisa e Estudos em Futebol - Universidade Federal de Viçosa

"* Doutor em Ciências do Esporte - Faculdade de Desporto da Universidade do Porto - Portugal - Professor Adjunto do Departamento de Educação Física NUPEF - Núcleo de Pesquisa e Estudos em Futebol Universidade Federal de Viçosa.

*** Doutor em Educação Física pela Universidade Gama Filho - Professor Associado da Universidade Federal do Rio de Janeiro (UFRJ) - Faculdade de Educação.
} 
live with feelings and meanings, at first glance, contradictory and irreconcilable: financial interest and passion. To support the hypotheses, we presented arguments of the media and fans that reinforce the permanence of the amateur ideal in the arguments used on transfers of two Brazilian players for European football at different times between the late twentieth and early twenty-first century. The first, Ronaldo Luis Nazario de Lima (The Phenomenon), who played in many European teams between the years 1994-2008, and the second is Neymar da Silva Santos Junior that was bought together with Santos F.C. by F.C.Barcelona in 2013.

Keywords: Football, passion, media, sport and economy.

O esporte moderno nasce no seio das escolas públicas inglesas como mais um princípio do processo educativo. Neste contexto educacional o esporte passa a representar uma forma civilizadora de polir os instintos humanos (agressividade, violência, paixão etc), tal como concebe Elias (1992). O esporte nos termos de Elias é uma mimese da guerra, mas uma guerra sem os riscos diretos do confronto armados. Todavia, rapidamente tornou-se também um ramo da ordem capitalista, onde a lógica basal é o acúmulo. E o esporte, ao ser governado pelos interesses passou a ser um local de negócios, apostas e divertimentos. Diante desta transformação, a manutenção do ideal amador teria sido apenas uma breve reação das elites em manter as barreiras de distinção social e frear a popularização que de certa forma feria, ou invadia, um de seus espaços para emulação de status, como descreve Veblen (1974). ${ }^{1}$ O esporte foi cultuado como um espaço propício para se demonstrar o ócio conspícuo, necessário ao status da aristocracia e, consequentemente, o amadorismo seria uma lógica desta predisposição de se fazer notar socialmente.

O objetivo deste texto é promover a reflexão sobre o processo de desenvolvimento do futebol no Brasil, focado nas tensões entre os ideais amadores e os valores do profissionalismo. O esporte a partir do momento em que assumiu o profissionalismo passou a conviver com sentimentos e significados, à primeira vista, antagônicos e inconciliáveis: interesse financeiro e paixão. Uma lógica econômica passa a ser

\footnotetext{
${ }^{1}$ No capítulo III - Ócio conspícuo, Veblen argumenta acerca da necessidade de demonstrar as façanhas honoríficas. “(...) À medida que aumenta a densidade da população e as relações humanas se tornam mais numerosas e complexas, todos os detalhes da vida sofrem um processo de elaboração e seleção; e neste processo de elaboração, o uso de troféus se desenvolve num sistema de posições, títulos graus e insígnias, no qual os exemplos típicos são os emblemas heráldicos, as medalhas e as condecorações honoríficas." (p.300)
}

empregada em consonância com ideais românticos (SALLES, 2004). Para sustentar as hipóteses apresentamos argumentações da mídia e dos torcedores que reforçam a permanência dos ideais amadores nos pressupostos utilizados acerca das transferências de dois jogadores brasileiros para o futebol europeu. O primeiro, Ronaldo Luís Nazário de Lima ( $o$ Fenômeno), que após ser contratado pelo Cruzeiro Esporte Clube em 1993 ganhou fama e rapidamente foi transferido para o futebol europeu, jogando em diversas equipes (PSV Eindhoven, F.C. Barcelona, F. C. Internazionale, Real Madrid C. F e A.C. Milan), ${ }^{2}$ o segundo é Neymar da Silva Santos Junior (Neymar Jr) ${ }^{3}$ que foi comprado junto ao Santos Futebol Clube pelo Futbal Club Barcelona em 2013. Veremos que apesar do profissionalismo ter se consolidado há mais de 80 anos no Brasil, ainda permanecem vivas as tensões acerca dos ideais amadores, trazendo ao campo esportivo uma rede de significados que sustentam o imaginário de alguns torcedores e da crônica esportivos sobre o 'dever ser' dos jogadores, quando estes se tornam pessoas públicas.

O modelo de esporte implantado pelos ingleses repercutiu mundo afora, e passou a ser uma referência para que as principais organizações esportivas. Entretanto, a partir do momento em que o esporte tornou-se um dos principais meios de entretenimento, rapidamente ocorreu uma nova perspectiva ao surgir à

\footnotetext{
${ }^{2}$ Considerado o melhor jogador do mundo pela FIFA (1996, 1997 e 2002), artilheiro da Copa do Mundo de 2002, maior artilheiro da história das Copas, presente em 4 Mundiais. Alguns cronistas e jornalistas o credenciam como um dos melhores jogadores brasileiros de todos os tempos.

${ }^{3}$ Neymar Jr, se revelou desde de muito cedo como um promissor jogador para o futebol brasileiro. Em sua curta trajetória esportiva acumula muitos títulos e prêmios, além de ter se tornado o principal garoto propaganda do futebol brasileiro nestes últimos anos. Foi campeão: Copa do Brasil 2010, Copa Libertadores da América 2011 e Recopa Sul-Americana 2012. Também foi medalha de prata nas Olimpíadas de Londres 2012.
} 
possibilidade do profissional esportivo. Obviamente, o surgimento desta bifurcação amadorismo/profissionalismo provocaria uma tensão entre os idealizadores do esporte (aqueles que o pretendiam apenas como um meio de distinção e refinamento, aliado aos ideais educativos) e alguns praticantes que rapidamente demonstraram outros interesses relacionados ao jogo.

O que parece ter ocorrido, é que ao se admitir o profissionalismo, colocava-se em jogo esse ideal educativo e moral, pois o esporte como ramo do negócio, parecia macular a competição, que passaria a ser governada pelo interesse. A competição passou a representar um local de demonstração da capacidade de empreendimento do clube inicialmente e mais tarde também dos seus patrocinadores. E o tipo de vínculo do atleta tornou-se o elemento basilar deste embate entre o interesse e os valores morais educativos. $\mathrm{O}$ interesse financeiro do atleta passou a ser questionado frente aos interesses da educação civilizatória do esporte (ELIAS, 1992).

Observemos que a desconfiança sobre a legitimidade e moralidade sobre o interesse estava presente no início do debate entre amadoristas e profissionalistas desde a transformação do esporte na Inglaterra. $\mathrm{Na}$ Inglaterra se questionava a credibilidade do jogador que gostava de dedicar exclusivamente a prática do futebol (MURRAY, 2000). Tanto os defensores do amadorismo, quanto àqueles que traçavam um novo modelo - o profissionalismo -, utilizavam os argumentos da dúvida no desenvolvimento de suas narrativas.

Essa velha desconfiança permanece, mesmo na atualidade. Em alguns momentos ainda se questiona o interesse do indivíduo sobre o esporte. Parece que o negócio no seio do esporte poderá corrompê-lo. Não se pode admitir o esportista mercenário, pois o homem que luta por dinheiro está sujeito a se corromper. Tal percepção se sustentava na mesma linha de raciocínio utilizada por Maquiavel (1999), quando alertara o Rei de Florença no século XIV sobre a composição dos exércitos mercenários. ${ }^{4}$ No futebol, mantém-se uma narrativa sobre a desconfiança de que o interesse do indivíduo, proporcionado pelo profissionalismo, possa corromper os valores educativos e morais que foram implantados e refinados pelos ideais amadores. Diante

\footnotetext{
${ }^{4}$ Maquiavel (1999) sugeria ao Rei que na composição do exército não admitisse soldados contratados. Ele propôs a composição de um exército patriótico sem os elementos mercenários por acreditar que o indivíduo lutar por dinheiro estaria sujeito a se vender para as tropas inimigas.
}

de tal desconfiança, como trabalhar com a ideia de transparência e credibilidade no esporte se cada jogador persegue seu autointeresse? Como manter o valor da honestidade se o jogador pode se vender individualmente? Essas são possíveis questões que pareciam pairar sobre a possibilidade de profissionalização do esporte no final do século XIX e primeiras décadas do século XX no Brasil.

A permanência de valores do amadorismo parece funcionar como uma espécie de contrapeso diante do medo de que o interesse individual (ou interesses) do atleta no campo do negócio supere os valores morais na competição. Há um medo explícito de que o negócio exacerbado faça com que se perca a crença na competição. Se isso ocorresse, seria ruim para todos, jogadores, dirigentes, patrocinadores e também a mídia.

Inicialmente o esporte com os ideais amadores se mantiveram num local de honra e glória. Era um espaço de destaque, distinto do local de interesse pela sobrevivência. Os indivíduos que o praticavam o faziam pelo prazer, pelo reconhecimento, pela honra e glória. Todavia, ainda no século XIX, o esporte atravessa as fronteiras das classes e passa a representar outras possibilidades para os praticantes, principalmente para aqueles que não poderiam continuar a praticá-lo descompromissadamente, tendo que dividir o tempo de dedicação ao esporte com o trabalho pela sobrevivência. Desta forma, o interesse individual frente ao esporte passou a substituir em parte, a honra e a glória nos termos aristocráticos. Obviamente que grande parte dos atletas inicialmente conciliavam tais propósitos, mas em períodos mais recentes essa conciliação não parece tão clara, sobretudo na percepção dos torcedores, dirigentes e da mídia e frequentemente torna-se questionada. Possivelmente Coubertin e seus aliados se sustentavam na perspectiva do vínculo esportivo incondicional, embasado apenas nos benefícios heroicos e de apuração humana, seja física, moral ou espiritual (DACOSTA, 1999). Os ingleses reformadores do esporte parecem ter bebido inicialmente nestas mesmas fontes.

Como o esporte moderno rapidamente passou a se estabelecer na lógica do interesse; um local de entretenimento coletivo, o treinamento e a eficácia passaram a exigir tempo e dedicação. Mesmo a elite praticante logo percebeu a dificuldade de se estabelecer em uma vida regrada que a competência esportiva exigia 
(divisão do tempo entre os compromissos diários e o treinamento necessário). ${ }^{5} \mathrm{Ou}$ teriam que se dedicar, ou contratar alguém para fazê-lo assim. Observemos que já estava em questão o apreço público, o consumidor do espetáculo esportivo. O praticante, aquele que o fazia por prazer e desinteressadamente, apenas com a sua dedicação amadora não seria mais suficiente para sustentar o anseio do torcedor que pagava para ver os jogos. Como adequar os interesses e as paixões que afloram desta interação dos distintos segmentos, em que cada qual busca sua própria lógica de vinculação? O esporte gera a conciliação de lógicas e interesses distintos.

O acúmulo de dinheiro através do trabalho tornou-se uma ordem admitida como forma de substituição das paixões violentas. O comércio passou a representar uma forma "douceur" (HIRSCHMAN, $2000)^{6}$ de conquista, diferente a pilhagem que ocorriam na época. Nesta perspectiva o acúmulo, o ganhar dinheiro de forma doce, tornou-se uma diretriz frequente na expansão do capitalismo (HIRSCHMAN, $2000)^{7}$. Segundo o autor para o surgimento do capitalismo foi necessário que o interesse entrasse como moderador das paixões. O esporte, na esteira desta expansão também teve que se adequar a estas novas configurações sociais. Como conciliar as apostas - que sempre estiveram associadas às competições esportivas -, o mercado de trabalho que surgia neste campo com os ideais aristocráticos do amadorismo?

Hirschman (2000) ao apresentar os pressupostos políticos para o capitalismo antes do seu triunfo argumenta que em algum momento da idade moderna o ganhar dinheiro passou a ser considerado superior ao

\footnotetext{
${ }^{5}$ Um bom exemplo deste fato pode ser percebido no filme Carruagens de Fogo, que conta à história de dois atletas que participaram dos Jogos Olímpicos de Paris, representando a bandeira da Inglaterra. Segundo Silva (1998), duas questões centrais são abordadas no filme: a identidade dos atletas (Herold Abrahams, era filho de um Judeu, nascido na Inglaterra e Eric Liddell que era filho de missionário escocês, nascido na China) e o amadorismo nos esportes ingleses, pautado nos valores das classes de elite. SILVA, L. H. O 1998. Carruagens de Fogo: notas sobre a institucionalização do esporte. In: Motus Corpores. Revista de divulgação científica do Mestrado e Doutorado em Educação Física. v.5. n.1 maio. Rio de Janeiro. Editora Central UGF.

${ }^{6}$ Esta expressão utilizada por Hirschman (2000) remete a ideia de doçura, mas o próprio admite a dificuldade de se traduzir esta expressão que foi utilizada pela primeira vez como qualificativo associado ao comércio por Jacques Savary, em sua obra La parfait négociant (livro destinado aos homens de negócio do século XVII, escrito em 1675). O comércio era visto como uma forma doce de acúmulos em comparação com o acúmulo em forma de pilhagem que acontecia em outras épocas.

${ }^{7}$ Hirschman (2000), enfatiza uma espécie de ruptura social, onde o novo nasce do velho e essa quebra que promove as transformações.
}

comportamento orientado pelas paixões. As análises desse autor se sustentam nos apontamentos de Hume, Smith, Mandeville, Santo Agostinho, Rousseau, entre outros. Inclusive Hirschmam enfatiza que, o que teria provocado o triunfo do capitalismo foi o fato da humanidade ter passado a admitir a busca da satisfação nos interesses materiais (o acúmulo), o papel de coibir as ingovernáveis e destrutivas paixões do homem. Durante longo tempo da história da humanidade essas paixões foram colocadas como pecado mortal da avareza. Para o autor as transformações sociais nascem da continuidade entre o velho e o novo, ao contrário de uma ruptura brusca conforme apontou Weber (2001) em A ética protestante e o espírito do capitalismo. Segundo Weber o ganhar dinheiro dentro de uma ordem econômica moderna, legalmente, é fruto do resultado da virtude e a proficiência de uma vocação. Esta ideia peculiar do dever profissional torna-se a mais característica da ética social da cultura capitalista; sua base fundamental.

No momento em que o futebol caminhava para o profissionalismo nos parece que o dilema principal se dava sobre o ganhar dinheiro no espaço do jogo, o que a classe detentora do poder sobre a organização e controle do esporte não queria admitir, julgando tal feito como perda dos ideais civilizatórios do esporte. Possivelmente os dirigentes esportivos desprezavam a possibilidade de que alguém pudesse demonstrar interesse econômico sobre um espaço que deveria ser destinado à confraternização de cidadãos refinados. Portanto, parece que o amadorismo esportivo quando estava sendo substituído pelo profissionalismo, e, evidentemente absorvendo princípios orientadores do capitalismo, teve o futebol e alguns outros esportes como espaço de resistência a lógica do dinheiro como princípio superior, principalmente para os dirigentes esportivos românticos e puritanos.

Apesar desta inquietude e repulsa quanto à possibilidade de ganho no esporte, rapidamente os dirigentes ingleses perceberam que deveriam ceder as pressões das classes operárias que pleiteavam as mudanças, sob pena de perderem o comando do esporte (SALLES, 2004). Desta forma, na Inglaterra se construiu um sistema dual: ligas amadoras e ligas profissionais. O sentido pragmático da cultura inglesa separou e distinguiu as elites por este mecanismo. Todavia, apesar da transformação exigida pelos 
operários praticantes o comando e controle do jogo permaneceram nas mãos das mesmas elites dirigentes.

Observemos que, o futebol que chegou ao Brasil pelos filhos de imigrantes que estudavam na Europa foi o do modelo amador das escolas europeias (PEREIRA, 2000). " 'Os sportmen cariocas transformaram um esporte praticado por operários das mais diversas procedências em um símbolo de elegância e sofisticação." (p.40). Contudo, o futebol rapidamente se populariza mantendo os ideais aristocráticos, conforme as denominações adotadas pelos ingleses. ${ }^{9}$ Esta popularização se deu, no entanto, para além das camadas privilegiadas da sociedade na época. Desta forma, o futebol no Brasil se tornou também um local de aposta, de sobrevivência e de entretenimento como ocorrera no velho continente, mesmo que inicialmente cravejado de preconceitos por parte da elite, quanto aos praticantes populares e seus interesses. ${ }^{10}$ Segundo Pereira, somente em 1907 apareceram nas páginas dos jornais, mais de 40 novas associações destinadas à prática do futebol, que se localizavam nas mais distintas regiões da cidade do Rio de Janeiro, do subúrbio ao centro. Ao final do século XIX o Brasil havia abolido a escravidão e sua população em expansão já era formada por união de diferentes raças: negros, índios, banco. Essa fusão de indivíduos de origens diferentes trouxe características bem singulares a cultura brasileira. $\mathrm{O}$ futebol obviamente, pela sua facilidade de prática e baixo custo, tornou-se rapidamente um elemento do lazer desta população em expansão.

O Brasil, nação em desenvolvimento, queria se repaginar sobre os ideais da cultura europeia e o futebol pela sua rápida aceitação passou a ser colocado como um destes mecanismos de afirmação cultural. (WITTER, 1990). Entretanto, porque ao copiar um modelo de desenvolvimento do esporte, optou-se pelo amadorismo e não pelo profissionalismo que já estava disseminado na Europa desde as décadas finais

\footnotetext{
${ }^{8}$ Pereira (2000) argumenta que os implantadores do futebol carioca, não observaram a grande difusão do futebol no país que foi seguido como modelo. Pereira argumenta ainda, que desde fins do século XIX que grandes contingentes de trabalhadores foram atraídos pelo futebol britânico e que estes indivíduos estavam longe do refinamento alardeado pelos esportistas cariocas. ${ }^{9}$ As denominações acerca do futebol mantinham até bem recentemente expressões da língua inglesa, tais como corner, back, offside, foot-ball, Keeper, linesman, full-back. (SANTOS, 1981).

${ }^{10}$ Pereira (2000) argumenta que ainda na primeira década do século XX "o futebol transformava-se num jogo praticado por grupos de diversos perfis sociais." (p.72) Ver Santos (1981). Essa é uma hipótese difundida na sociedade brasileira.
}

do século XIX? Obviamente que esta interrogativa ingênua é de fácil resposta. Os primeiros dirigentes brasileiros eram filhos das elites e para eles o que importava primordialmente era o status social. O ganhar dinheiro no espaço do jogo soava com uma desfaçatez para uma classe de privilegiados. O esporte constituiu desde cedo na sociedade brasileira em um local apropriado para ancorar tradições românticas (CAMPBELL, 2001). ${ }^{11}$

Entretanto, os dirigentes esportivos brasileiros perceberam que, o futebol ao ganhar corpo na dinâmica social fomentava novos mecanismos de sustentabilidade. Não havia mais espaço apenas para aquele futebol de refinamento e confraternização da classe endinheirada. O prestígio dos seus clubes só seria possível através das vitórias. E essa necessidade de vitória levou rapidamente a busca da competência, onde a valorização do jogador passou a ser condicionada a sua capacidade de promover o bom entretenimento. Nesta perspectiva, tornava-se necessário abrir as portas dos clubes (mesmo que apenas do campo de futebol) para indivíduos de outras classes, sem o rigoroso crivo social apregoado pelos associados. Isso parece ter sido uma prática usual utilizada pelos principais clubes à época. Alguns jogadores das camadas populares almejavam jogar nos grandes clubes e por isso, admitiam que seus vínculos inicialmente se dessem apenas no território do jogo. ${ }^{12}$

$\mathrm{Na}$ fase de consolidação do futebol no Brasil (entre o final da década de 10 e década de 20 do século $\mathrm{XX}$ ) os ideais amadores passaram a ser questionados (SANTOS, 1981). ${ }^{13}$ Parece que o desenvolvimento do

\footnotetext{
${ }^{11} \mathrm{O}$ conceito de romantismo seria fruto de um grande movimento intelectual e artístico surgido no final do século XVIII no ocidente, que segundo Campbell (2001) tornar-se de difícil definição por três motivos: $1^{\circ}$ ) o fenômeno compreende o desenvolvimento em quase todos os campos da vida intelectual e cultural; $2^{\circ}$ ) as mais influentes definições teriam sido formuladas por antagonistas; e $3^{\circ}$ ) Deve ser entendido como um impulso, e não como um sistema unificador de ideias. Seria um impulso para o caos. "Uma definição fechada do romantismo... não é muito romântica", como "se um importante aspecto do romantismo é a rebelião, então rebelar-se contra o romantismo também podia ser romântico." (p.252). Para nosso propósito, sem, no entanto, ter a pretensão de se reduzir à dificuldade apontada por Campbell, iremos adotá-lo grosso modo, como uma atitude, um comportamento que desperta o sentimentalismo exacerbado, o individualismo. Modo de ser do indivíduo que é muito sonhador, sentimental, emotivo etc. Atitude do indivíduo que é desprovido de prudência prática, de senso de realidade, aquele que se deixa guiar pela imaginação, se entrega ao devaneio de forma irracional.

${ }^{12}$ Outra estratégia também utilizada foi à criação de uma categoria denominada de sócio jogador. Uma espécie de autorização para que estes jogadores tivessem alguma "liberdade" nas dependências dos clubes (SANTOS, 1981). ${ }^{13}$ Santos (1981) argumenta que esse conflito também teria ocorrido nos rádios, ao trocar o sistema de sócios pelos anúncios.
} 
esporte (e do futebol), aqui como em qualquer lugar, não poderia se manter amador diante do processo de popularização e consolidação em uma sociedade que tentava se estabelecer como capitalista.

Desde os anos finais da década de 20 até o ano de 1933 permanecia o debate acerca do perfil esportivo que deveria ser seguido no Brasil. Interessante observar que, embora esta tensão pudesse ser fruto da pressão provocada pelas classes populares, era travada pelos membros da elite. De um lado, os defensores do profissionalismo que acreditavam no desenvolvimento do esporte e da ascendente indústria do entretenimento, e, do outro, os defensores do amadorismo que desejavam manter os ideais aristocráticos e a adequada sociabilidade entre as "boas famílias". Naturalmente que os amadoristas saíram derrotados, pois a lógica do desenvolvimento da indústria do futebol não deixava espaço para a manutenção de todos os ideais. Caldas (1990) relata que, a partir da implantação do profissionalismo, os quadros amadores não conseguiam mais manter a atenção dos torcedores que compareciam aos campos para assistir os quadros profissionais. Pagavam ingressos para ver a equipe principal formada pelos profissionais. Os jogos entre os amadores eram apenas uma atração preliminar. Um cronista esportivo referiu a esses encontros amadores como "amansa sol", uma vez que os profissionais somente jogavam ao final da tarde, depois que a temperatura estivesse branda e o efeito do sol já não provocasse tanto desgaste. (REVISTA FON-FON, 03 de ago/1933, p.7)

Todavia, os argumentos dos pro-profissionalistas não excluíam os ideais civilizatórios do esporte e também não perdia de vista o temor que as relações explícitas em termos financeiros poderiam provocar ao desenvolvimento do futebol em geral, bem como aos seus respectivos clubes. Tanto temiam assim, que algumas limitações adotadas ainda no período do amadorismo foram mantidas para os clubes que pretendiam participar das competições, (como, por exemplo, ter sede social e campo de futebol, arcar com joia de admissão ${ }^{14}$ e o jogador deveria saber ler e escrever.) Também posteriormente ao processo de profissionalização outras ações foram implantadas, tais como: valores máximos dos salários e tempo mínimo

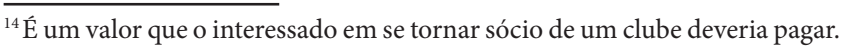
Hoje essa taxa é denominada de cota. Cada clube, em função da sua estrutura e grupo social a qual se destina tem um valor específico. É uma estratégia de controle sobre o perfil do associado.
}

de permanência no clube. Tratava-se de medidas que assegurassem a ordem, evitando as querelas entre os clubes e os jogadores contratados. O mercado profissional foi regulado.

Rapidamente ao se admitir o profissionalismo, novas diretrizes passaram a ser colocadas em contrapeso aos ideais do amor. E mesmo passado quase um século da transformação do regime algumas narrativas são reacendidas na atualidade.

Mesmo diante de todas as possibilidades de acúmulos valorizadas pela sociedade, o ganhar dinheiro no futebol, às vezes, ainda aparece maculado, estranho e perverso na narrativa de alguns torcedores $\mathrm{e}$ românticos da mídia. Por que ganhar tanto dinheiros? Em uma sociedade dominada pela pobreza, como é grande parcela da população brasileira, isso soa como algo de espírito menor, que parece ferir a essência do homem, em uma narrativa puritana.

Assim constata-se que em algumas situações o discurso profissionalista é enfatizado no sentido de contrapor-se ao comportamento dos atletas que tomam o esporte, o jogo sem a seriedade requerida. Neste sentido, o discurso que aborda o amadorismo e o profissionalismo tem uma estrutura pendular, tendendo-se para o lado que no momento da discussão em questão for capaz de corresponder ao apelo emocional e as expectativas dos atores envolvidos (torcedores, dirigentes, imprensa e os próprios jogadores). Ambos, amadorismo e profissionalismo sustentam-se numa demanda de cunho emotivo. O jogador de futebol é, por excelência, uma figura pública e célebre na sociedade brasileira.

Vejamos como os atores sociais especulam os motivos dos jogadores diante de suas transferências. Parecem esquecer por algum momento do direito profissional da busca por melhores salários e, assim, criam uma rede discursiva que opera no sentido de dramatizar e questionar os fatos.

Ronaldo, "o Fenômeno”, foi o jogador brasileiro de futebol mais premiado nos últimos anos. Em sua transferência da Internazionale de Milão para o clube Real Madrid após a Copa do Mundo de 2002, protagonizou uma polêmica internacional, gerando um discurso de desconfiança sobre sua atitude profissional. Uma transação que poderia ser considerada apenas como uma das mais vultosas transferências de 'mão de obra' de um jogador na época, tornou-se notoriedade pelo 'sentimento de ingratidão' que animou 
o processo de negociação, como foi apontado pelos jornais esportivos espanhóis, italianos e brasileiros. A Internazionale teria investido grande soma de recursos e esperado pacientemente a recuperação do jogador, que ficara por quase dois anos fora dos gramados, devido a uma grave lesão. Porém, quando se recuperou e tornou valorizado no mercado, resolveu ir para outro clube, o Real Madrid. Vejamos algumas narrativas:

Para o Jornal Lance (3 de set/2002, p.22), "Ronaldo foi um ingrato com a Inter. O clube sempre fez tudo por ele não merecia essa traição". O jornalista Marcelo Damato colocou que "a crise entre Ronaldo e a Internazionale está jogando sombra naquele que deveria ser o momento mais brilhante da carreira do Fenômeno" (JORNAL LANCE, 7 de ago/2002, p.3).

Oscar Valporto (Jornal O Dia) questionou: "Ingrato ou mimado?" Para o jornalista, Ronaldo "tem todo o direito de procurar o melhor para sua vida e sua carreira", mas o acusou de não ter agido decentemente:

"Ronaldo, sempre tão preocupado com a imagem, agiu da pior maneira possível para trocar de clube. Depois da Copa, fez questão de mandar juras de amor a Inter e a torcida italiana. Na sexta-feira, quanto entregava generosa doação ao Instituto do Câncer e a Fundação Gol de Letra contava ao pé do ouvido de um jornalista que esta a caminho do Real Madrid." (Coluna Linha de fundo - JORNAL O DIA, 8 de ago/2002.p. 4).

Valporto fala em juras de amor ao clube e a torcida. Observemos como a imprensa vem trabalhando as imagens de amor e pertencimento invocando questões pessoais na relação que, a piori, deveria ser apenas trabalhista.

"Quer ganhar mais do que Recoba e Vieri? Tem medo de ficar na reserva? Não gosta do treinador? Detesta falar italiano? Quer fica longe da mulher, que vai jogar num time feminino da cidade? Todos esses seriam motivos razoáveis, mas talvez, pouco diplomáticos. Desmascarada a tentativa de sedução ao Real, Ronaldo manda dizer pelos assessores apenas que "não está feliz em Milão". Sem qualquer outra explicação, fica parecendo birra de criança. Mimada, muito mimada." (JORNAL O DIA, 8 de ago/2002. p. 4).

A insatisfação dos torcedores da Internazionale perante a atitude de Ronaldo gerou vaias e faixas e insultos nos jogos seguintes a essa discussão. Parte da imprensa italiana também demonstrou seu repúdio ao que eles consideraram ingratidão do jogador. Um jornal italiano o classificou com mercenário. Para ilustrar a reportagem, apresentaram uma figura contendo cédulas de euros (denominadas de Euronaldo), tendo o rosto do jogador como símbolo da moeda. Essa mesma imagem foi reproduzida no Jornal O Dia no Brasil (09 de ago/2002, p.4). O jornal Lance satirizou a situação, ao publicar uma charge com a caricatura de Ronaldo utilizando um brinco pendurado em forma de etiqueta de preço contendo o símbolo cifrão (\$). (JORNAL O DIA, 18 de ago/2002, p.3).

Observa-se que a imprensa e seus articuladores narram o "espetáculo" fora do campo de futebol com ambiguidade e suspeição semelhantes às dos torcedores.

Esse episódio da transferência do Ronaldo foi oportuno para observarmos como as narrativas se vinculam às denúncias de pertencimento e amor do jogador com o clube em diferentes tempos ao longo do processo profissional do esporte. O jogador deve apresentar uma postura profissional, a qual, todavia, necessita ser sempre permeada pelo comprometimento afetivo. $\mathrm{O}$ discurso de ordem racional deve interagir com os de ordem emocional (SALLES, 2004). Apenas o profissionalismo não faz sentido em um espaço dominado pela emoção; algo que se valoriza com grande apreço nas demais profissões.

A transferência do Neymar da Silva Santos Junior (Neymar Jr) para o Barcelona também mexeu com o imaginário social reacendendo os ideais amadores no campo das ações financeiras. Durante vários anos se especulou sobre a saída de Neymar do futebol brasileiros. Diversos argumentos estiveram presentes nas narrativas dos dirigentes, técnicos, empresários, jogadores e torcedores. Desde seu surgimento na equipe sub-11 do Santos Futebol Clube, vinha despertando o interesse da mídia especializada brasileira e dos torcedores. Aos 14 anos ele teria desembarcado na Espanha visando realizar um estágio no time do Real Madrid. Entretanto, os dirigentes do clube Santista, percebendo o risco de perder seu promissor jogador, teriam pagado a quantia de um milhão de reais para que ele permanecesse no clube até tornar-se profissional, o que ocorreu aos 17 anos em 2009.

Desde aquele momento já se sabia que ele sairia do clube rumo ao futebol europeu. A questão passou a ser quando isso ocorreria. Após o Mundial Interclubes 
de $2011^{15}$ ou após a Copa do Mundo de 2014? Este fato se consolidou no mês de maio de 2013. ${ }^{16}$ Até aquele momento, a oitava maior transação do futebol internacional. ${ }^{17}$ Entretanto, uma expectativa que já estava previamente definida ainda reacendia o discurso de ordem amadora como normativa das ações, conforme se observará nas argumentações dos torcedores santistas diante de algumas reportagens eletrônicas sobre esta transferência. ${ }^{18}$

Bom, vamos as questões: Qual é a lógica de tanto acúmulo? Esse garoto já não tem dinheiro suficiente para as suas futuras gerações? Onde localiza o prazer de jogar bola diante dessa voracidade por ganhar dinheiro? Em Barcelona será uma estrela, ou mais uma frustração esportiva enriquecida? (...) Quanto ao amor dele pelo Santos; ah... já vimos tantos outros beijando o escudo e a bandeira, chorar e dizer que um dia volta. Apenas mais um! E quem no futebol brasileiro não fez isso? (...) A quem vai toda essa grana, não me interessa. Continuarei Santos, pois o Clube para mim é mais do que os personagens. Sucesso, muito sucesso para você, querido Neymar. (Alba Sá) ${ }^{19}$

Observemos que, embora a torcedora Alba Sá se diz desinteressada em saber para quem vai o dinheiro desta transação, ela não consegue se desvencilhar desta questão. O ganhar dinheiro é colocado no discurso como algo perturbador, ainda que tratado na falsa indiferença. Em seu discurso a torcedora retoma os ideais amadores sustentados no amor a camisa e aos símbolos, tão comum nos gramados brasileiros ao longo destes 80 anos de profissionalização do futebol.

\footnotetext{
${ }^{15}$ Neymar participou do Mundial Interclubes promovido pela FIFA no Japão, representando a equipe do Santos, em que foram vice-campeões.

${ }^{16} \mathrm{O}$ jogador usa a sua rede social para anunciar sua decisão de aceitar a proposta do Barcelona.

Neymar é do Barcelona! Atacante confirma saída para clube espanhol. Disponível em: http://www.lance.com.br/todos-esportes/neymar-barcelona-atacante-confirma-saida-clube-espanhol.html. Acessado em 21 de junho de 2013

17 "Neymar fechou com o Barcelona pelas próximas cinco temporadas, com um custo total de $€ 57$ milhões. Este custo total inclui direitos federativos e econômicos", explicou Josep Maria Bartolomeu, vice-presidente de futebol do Barcelona. http://esporte.ig.com.br/futebol/2013-06-03/transferencia-de-neymar-para-barca-e-a-oitava-mais-cara-da-historia-veja-lista.html. Acessado em 10 de outubro de 2013.

${ }^{18}$ Os sites disponibilizam espaços para que os interessados possam comentar as reportagens. Portanto, os argumentos dos torcedores santistas foram extraídos destes comentários, conforme endereços eletrônicos nas notas abaixo. ${ }^{19}$ Fora do top 50 das transferências, Neymar custa menos ao Barça do que outras estrelas. Portal UOL. 26 de mai/2013. São Paulo. http://esporte.uol.com. br/futebol/ultimas-noticias/2013/05/26/fora-do-top-50-das-transferencias-neymar-custa-menos-ao-barca-do-que-outras-estrelas.htm\#comentarios Acessado em 10 de junho de 2013.
}

Eu não entendo. Aqui ele é Rei. Agora vai ser coadjuvante de Messi e Cia. Tudo pensando em ganhar mais dinheiro. Para que? O que lhe falta? E disse ainda que ama o Santos. Será? Um amor que só pensa em dinheiro. Não dá para acreditar. (João Carlos) ${ }^{20}$

Não basta ser o jogador mais bem pago e prestigiado do futebol brasileiro? Aqui ele é o cara... Ainda que os demais torcedores dos outros clubes sejam recalcados e digam que não. Mas, o fato é que ele é. Lá fora pode não dar certo. E ai voltará desmoralizado. Me parece que ele não tem maturidade para permanecer fora do Brasil. Por outro lado é um sonho alimentado desde garoto. Por mais que eu gostaria que ele ficasse, eu entendo que como qualquer outro que já foi, ele também tem o direito. Tenho convicções que ele ama o Santos, mas no futebol amores vem e vão. Chora a viúva! (Gualberto Azevedo) ${ }^{21}$

O torcedor João Carlos questiona os mesmos valores. Onde está a representação do amor? Vejamos a desconfiança sobre a ideia de amar e comercializar esse amor. $\mathrm{O}$ torcedor Gualberto Azevedo questiona: "Não basta ser o jogador mais bem pago e prestigiado do futebol brasileiro?" Obviamente que tais representações são reflexos das inquietudes de alguns românticos sonhadores de um futebol puritano, como foi aquele pretendido pelos filhos da elite brasileira no início do século passado.

Vejamos que a insatisfação do torcedor Gualberto é canalizada para a desconfiança de que lhe faltaria maturidade para residir fora do Brasil. A ideia de que ele é um jogador promissor parece ser retirada da narrativa de forma a trazer alento as angústias como torcedor. O discurso é conduzido para a ideia do direito ao sonho, desvinculando do direito profissional. O discurso emocional parece sobrepor a qualquer outro entendimento da questão.

É por isso que está dessa forma Gualberto Azevedo. Amores que vem e vão? Isso não é amor. Ninguém tem sentimentos sinceros para com o clube. São

\footnotetext{
${ }^{20}$ Transferência de Neymar para Barça é a oitava mais cara da história - Clube catalão confirmou que desembolsou um total de 57 milhões de euros (cerca de R \$ $159 \mathrm{mi}$ ) pelos direitos federativos e econômicos do atleta. Portal iG São Paulo 03 de jun/2013 http://esporte.ig.com.br/futebol/2013-06-03/ transferencia-de-neymar-para-barca-e-a-oitava-mais-cara-da-historia-veja-lista.html. Acessado em 10 de junho de 2013.

${ }^{21}$ Olho Crônico Esportivo. Emerson Gonçalves. A questão da transferência de Neymar: aberta e complicada. 03 de jun/2013. Disponível em: http://globoesporte.globo.com/platb/olharcronicoesportivo/2013/06/05/a-questao-da-transferencia-de-neymar-aberta-e-complicada/. Acessado em: 11 de junho de 2013.
} 
todos mercenários que só pensam em dinheiro. Muito, muito dinheiro. Que ele tenha o direito de ir, que seja sonho de garoto, eu até entendo. Mas, trocar o Santos por questão financeira é um absurdo. Ninguém teve tanto privilégio com ele na Vila. E se falar em dinheiro então. Ele nem sabe quanto de dinheiro tem. É uma pena! Eu temo pelo que ocorrerá com o nosso time nestes próximos anos. (Ana Maria). ${ }^{22}$

Sobre a argumentação do torcedor Gualberto Azevedo, a torcedora Ana Maria contesta os mesmos fatos de forma mais revoltosa, acusando os jogadores de mercenários. Ela diz não acreditar no amor de Neymar para com o clube e lamenta que a transferência tenha sido por questões financeiras. Entretanto, deixa claro que sua preocupação é com o rumo da equipe sem a presença de Neymar. Vejamos com os discursos deslocam a questão profissional, aos pontuarem prioritariamente as questões afetivas dos sentimentos frustrados diante de uma transação trabalhista.

Pelé, o maior jogador da história do futebol mundial também tragado pela narrativa romântica apresenta sua visão sobre o processo de transferência, mostrando-se chateado pelo fim da identidade que os jogadores criavam frente aos seus clubes. $\mathrm{Na}$ visão do Pelé:

"É lamentável, não tenha dúvidas que é algo triste. Eu tive proposta para ir para todo time da Europa, mas estava bem no Santos, e naquela época era diferente. O Santos estava em uma fase boa, e não saí. Agora tem os empresários, que não pensam nos clubes quando pegam o jogador. Ele está pensando no que vai faturar e isto é triste hoje. Antes, o jogador queria ficar para o resto da vida no clube de coração. Hoje, joga um, dois anos e o empresário coloca em outro clube. É algo chato o que aconteceu com o Neymar".(CORREIO DO POVO, 2014) $)^{23}$

O profissionalismo parece ter surgido como uma nova regra que se impunha na organização esportiva mundial, principalmente pela valorização do espetáculo. Nesta perspectiva o profissionalismo seria a visibilidade de comercialização deste espetáculo. A imagem espetacular passou a produzir interesses e valores diferenciados. O torcedor como consumidor,

\footnotetext{
${ }^{22}$ Idem, nota anterior. Acessado em: 13 de junho de 2013.

${ }^{23}$ Pelé lamenta imbróglio sobre venda de Neymar e teme repercussão futura. Disponível em: http://www.correiodopovo.com.br/Esportes/?Noticia=517463. Acessado em 22 de fevereiro 2014.
}

neste processo de desenvolvimento socioeconômico se vê frustrado diante de sua dedicação diante do cenário em que o comércio dita a regra do jogo. Atualmente o futebol profissional em sua dimensão macro não pode ser pensado sem estar vinculado ao mundo do negócio, a indústria e a mídia. (SALLES, 2004).

$\mathrm{Na}$ lógica de uma sociedade capitalista, em que o esporte foi transformado em fonte de lucro, os ideais heroicos e de honra relacionados ao amadorismo tiveram que combinar com o interesse. Obviamente para alguns torcedores isso pode ser contraditório, quando pensam essa relação a partir da moral cristã: “o amor não se compra!” Para a imprensa, no entanto, essa tensão parece ser útil, na medida em que precisa dela para manter acessa essa polêmica orientada pela demanda de seus leitores. O discurso amador nessa perspectiva racional proveniente do interesse passou a ser funcional, uma espécie de regulação do comportamento dos profissionais.

\section{REFERÊNCIA BIBLIOGRÁFICA}

CALDAS, W. 1999. O pontapé inicial: memória do futebol brasileiro (1894-1933). São Paulo. Ibrasa.

CAMPBELL. C. 2001. A ética romântica e o espírito do consumismo moderno. Rio de Janeiro. Rocco.

DACOSTA, L. P. 1999. O olimpísmo e o equilíbrio do homem. In: Tavares, O. \& DaCosta, L. P. Estudos Olímpicos. Rio de Janeiro. Editora Gama Filho.

ELIAS, N. 1992. A busca da excitação. Lisboa. Disfel.

HIRSCHMAN, A. O. 2000. As paixões e os interesses. Rio de Janeiro. Paz e Terra.

JORNAL O DIA (8 de ago/2002. p. 4); (09 de ago/2002, p.4); (18 de ago/2002, p.3).

JORNAL LANCE (7 de ago/2002, p.3); (3 de set/2002, p.22).

MAQUIAVEL, N. 1999. O príncipe. São Paulo: Nova Cultural Ltda.

MURRAY, B. 2000. Uma história de futebol. São Paulo. Hedra.

PEREIRA, L. A. de M. 2000. Footballmania - Uma história social do futebol no Rio de Janeiro, 1902-1938. Rio de Janeiro. Nova Fronteira.

Revista Fon-fon, 03 de ago/1933, p.7. 1907 
SALLES, J. G. do C. 2004. Entre a paixão e o interesse $\mathrm{O}$ amadorismo e o profissionalismo no futebol brasileiro. (Tese de doutorado). UGF. Rio de Janeiro.

SANTOS, J. R. 1981. História Política do Futebol Brasileiro. São Paulo. Brasiliense.

SILVA, L. H. O. 1998. Carruagens de Fogo: notas sobre a institucionalização do esporte. In: Motus Corpores. Revista de divulgação cientifica do Mestrado e Doutorado em Educação Física. v.5. n.1 maio. Rio de Janeiro. Editora Central UGF.

WEBER, M. 2001. A ética protestante e o espírito do capitalismo. São Paulo. Pioneira Thomson Learning.

VEBLEN, T. 1974. A teoria da classe ociosa - Um estudo econômico das instituições. Os pensadores. Rio de Janeiro: Abril Cultural.

WITTER, J. S. 1990. O que é futebol. São Paulo. Brasiliense. 